\title{
Juvenile Sublingual Dermoid Cyst
}

\author{
Swathi Shammi1 ${ }^{1}$, Ramvihari Thotaㄹ, Abdul Wahab P. U.3 , Pradeep Dhasarathan4, Senthil Murugan. P5 \\ 1, 2, 3,4,5 Department of Oral and Maxillofacial Surgery, Saveetha Dental College and Hospitals, Saveetha Institute of \\ Medical and Technical Sciences, Saveetha University, Chennai, Tamil Nadu, India.
}

\section{INTRODUCTION}

Congenital cystic lesions of the oral cavity are extremely rare. The differential diagnosis of intraoral cystic lesions includes ranula, lymphatic malformation, dermoid cyst, epidermoid cyst, and teratoma. ${ }^{1}$ Histologically, all dermoid cysts are lined by epidermis-like epithelium and contain dermal adnexal structures such as skin, muscle, bone and cartilage. ${ }^{2}$

Also known as "epithelial inclusion cysts", dermoid cysts are congenital in origin which are caused by the encasement of ectoderm at the time of closure of an embryogenic tissue. Contains sebaceous glands and secretions. Rarely, may contain hair and hair-like follicles. Usually they appear at the time of birth. They become evident as years progress and achieves maximum growth at the time of puberty. They occur frequently in the floor of the mouth and also in the submental region.

Dermoid cysts occur in the region where embryonic parts fuse together. Most of them occur in the midline of the body, as well as in the ovaries and in the testicles. No gender predilection is there for dermoid cyst occurrence. Their presence becomes prominent in the second or third decade of life as slowly enlarging masses. The treatment is surgical removal of the cyst. ${ }^{3}$

\section{PRESENTATION OF CASE}

A 3-year-old girl was referred to our department for diagnosis and treatment of $3 \times 3$ $\mathrm{cm}$ mass in the floor of mouth. History reveals that it was first noted 3 years ago at the time of birth. A small, painless, asymptomatic nodule in the floor of mouth was excised at the time of birth which had again recurred. The mass gradually increased in size over the next 3 years and it stabilized to its present size. No pain or discomfort was associated with the lesion. However, as it enlarged the patient had difficulty in mastication. No difficulty in speech. Discovered during routine dental examination.

Examination reveals no limitation of movement of jaws. Large mass noted protruding in the floor of mouth between tongue and mandibular anterior teeth. Mass is accentuated as the patient raises the tongue. Limitation of movement of tongue was evident. Pressure in the submental region caused the mass to be prominent in the floor of mouth. Mucosa is tensed over the underlying mass (Figure 1).
Corresponding Author: Dr. Swathi Shammi,

Department of Oral and Maxillofacial Surgery, Saveetha Dental College and Hospitals, Saveetha Institute of Medical and Technical Sciences, Saveetha University, No. 162, Poonamallee High Road, Velappanchavadi - 600077, Tamil Nadu, India.

E-mail: swathisshammi@gmail.com

DOI: $10.14260 / \mathrm{jemds} / 2020 / 789$

How to Cite This Article:

Shammi S, Thota R, Wahab PUA, et al. Juvenile sublingual dermoid cyst. J Evolution Med Dent Sci 2020;9(47):35923595, DOI: 10.14260/jemds/2020/789

Submission 01-07-2020,

Peer Review 25-08-2020,

Acceptance 02-09-2020,

Published 23-11-2020.

Copyright (c) 2020 Swathi Shammi et al. This is an open access article distributed under Creative Commons Attribution License [Attribution 4.0 International (CC BY 4.0)] 


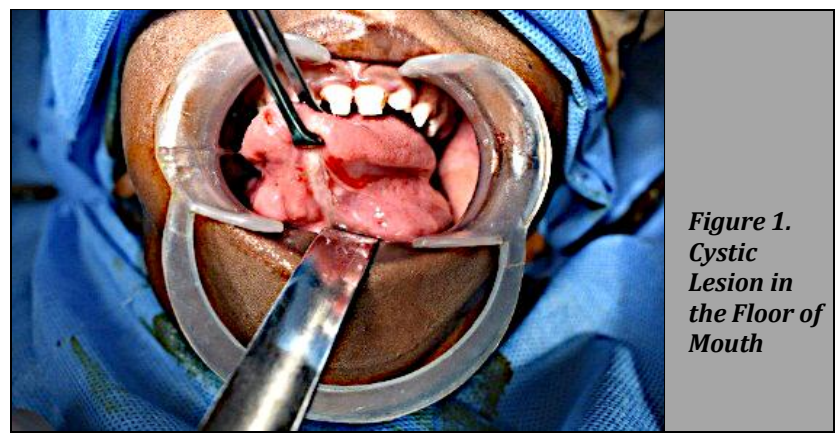

On palpation, the mass had a firm, rubbery consistency. The mass was slightly compressible. Firm resistance was encountered though. As the mucosa moves, it moves freely and independently of underlying mass giving the impression that a distinct capsule surrounds the submerged lesion.

An intraoral surgical approach was chosen to excise the suspected ranula in the floor of mouth. To obtain additional information, aspiration to determine the contents of mass would be helpful. To carry out this diagnostic procedure, anaesthesia is required. GA was selected for aspiration procedure and subsequent surgery. A wide bore needle is inserted into the substance of mass. Needle was placed in several different areas of the mass and eventually an area was encountered which yielded a small amount of thick, yellowish white caseous material. Aspiration of yellowish, white thick caseous material established the fact that there is a sebaceous like substance in the central portion of the mass and pointed to "epidermoid cyst" as tentative diagnosis. Surgery in the floor of mouth presents several problems. On either side of the midline are noted the openings of submandibular duct and the surgery should not injure these important structures. Large vessels and nerves must be avoided (Figure 2).

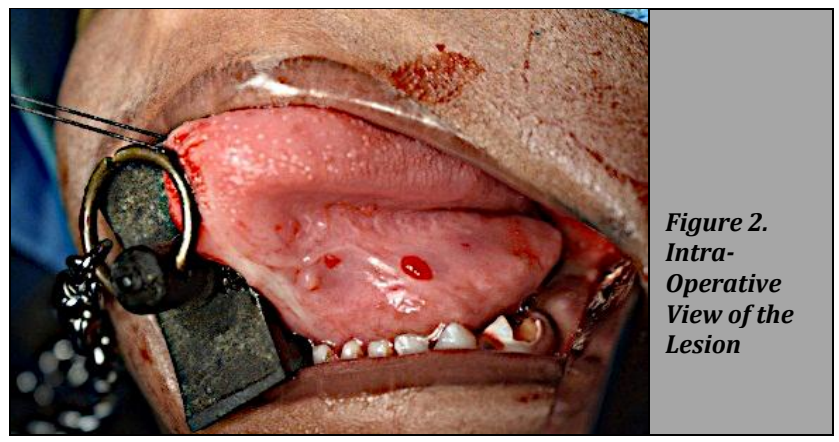

Incision was made through mucosa being careful to avoid the submandibular duct. Incision was made carefully to avoid incision of the underlying capsule. Incision of the capsule would release the contents of the cyst into the wound making the surgery difficult. Dissection through mucosa was progressed carefully until the capsule of the overlying mass was completely exposed. Blunt dissection is done in the floor of the mouth as it is a very vascular region.

Following incision of mucosa, scaffold was discarded, and mass was separated from the surrounding connective tissue by blunt dissection (Figure 3). Distinct capsule was noted surrounding the mass and distinct plane of separation developed. As the superior and lateral aspects were freed, the mass began to protrude into the exposed area. To reach the depth of mass, a curved curette was used to release the fibrous attachments and as the dissection proceeds mobilization of mass became evident. The dissection reaches the depth where the use of curette is no longer effective. Blunt dissection was carried deeper using a small piece of gauze in the haemostat. With the dissection continuing medially, a smooth, spherical shaped cystic lesion was noted in close proximity to the sublingual gland (Figure 4). As the mass became more mobile, traction was applied.
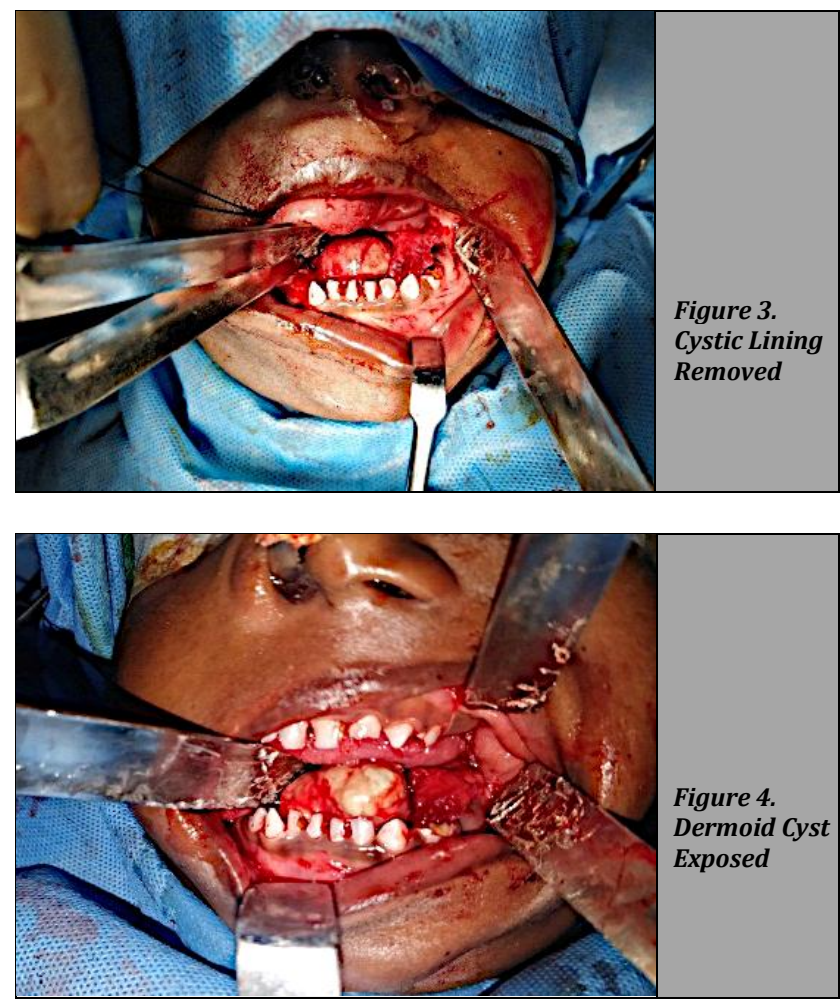

This permits access to deeper attachments. Lingual nerve and submandibular salivary gland duct were both preserved. These were separated and the mass was delivered from the wound (Figure 5). Cystic lesion was removed in toto without any damage to the surrounding structures and primary closure was done. Freeing the mass without the rupture of capsule, maintaining the integrity of capsule facilitates surgery and prevents contents of mass from escaping into operative wound.

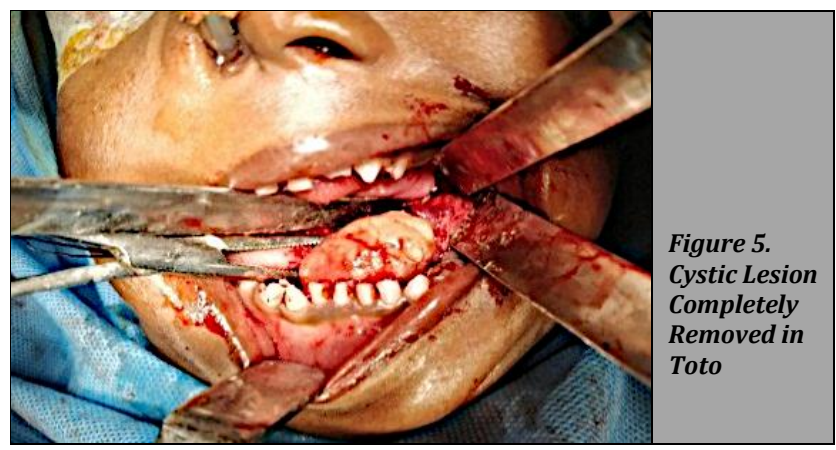

The excised mass was large, firm, distinctly encapsulated lesion that offers firm resistance to compression (Figure 6). As it is compressed, some of thick material was seen extruding from the opening in the capsule that resulted from aspiration. The consistency of this material explained the difficulty that was encountered when the aspiration procedure was carried out. 


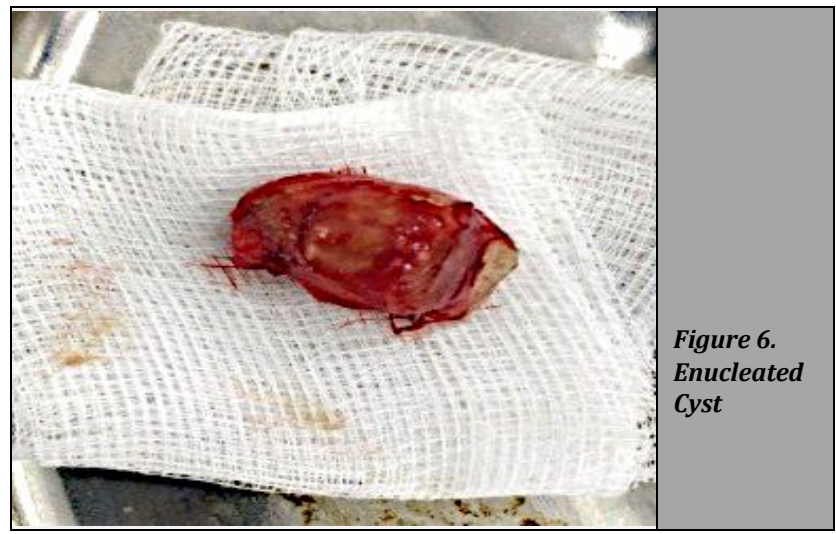

The operative defect is examined carefully to ensure complete haemostasis and removal of all fibrous tissue tags. (Figure 7)

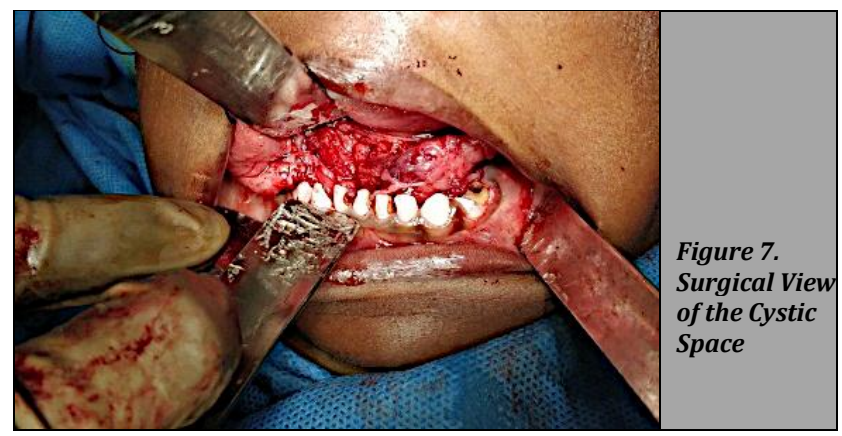

The wound is then ready for closure. As operative defect of considerable size remains, this defect must be eliminated. The mass developed planes of separation and extravasated blood and serum might occupy these planes to produce haematoma and thus delay healing. Since the mass has displaced muscle tissue, there is a tendency for the displaced muscle mass to return to their original position and assist in obliteration of defect. To further collapse the wound, absorbable sutures are placed in the deeper muscle layers. These deep sutures are placed in sufficient number to eliminate all dead space. Closure of mucosa is an important step. Suture is passed through the mucosal flap on right side, muscle tissue and then through the mucosal flap on the left side.

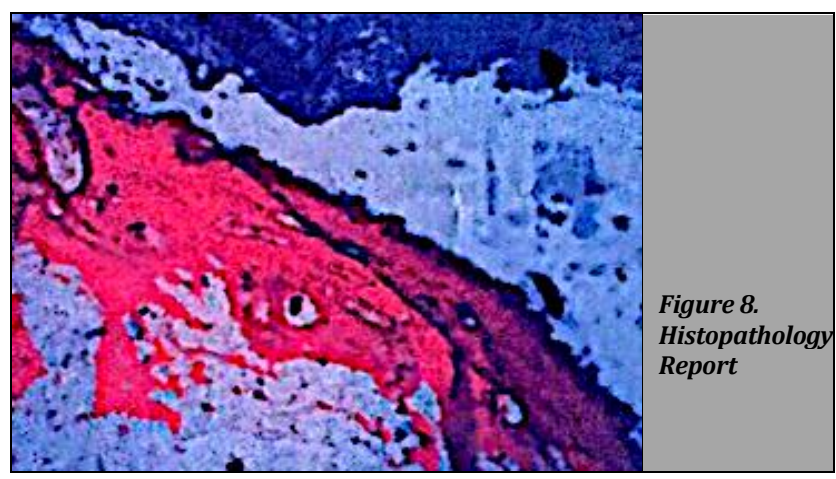

The histologic section of the specimen (Figure 8) revealed stratified squamous epithelial lining and connective tissue wall containing sebaceous acini along with hair appendages. The cystic lumen was filled with numerous flakes of keratin and the deeper planes showed adipose tissue.

The patient was admitted for a day for observation and was discharged home the next day with an uneventful stay.
Following one week postoperatively, the incision site was healing well and the patient had normal speech and mastication without any difficulty.

\section{DISCUSSION}

Dermoid cysts are benign lesion arising from totipotent stem cells that undergo ectodermal differentiation. Grossly, these cysts are thin walled ( $2-6 \mathrm{~mm}$ thick) and contain oily, pale yellow keratinous material. ${ }^{4}$ Nearly $34 \%$ of the dermoid cysts are found in head and neck region of which $6.5 \%$ are located below the tongue in the floor of mouth.

Dermoid cysts are broadly classified as congenital and acquired cystic lesion. ${ }^{5}$ There are 3 theories with regard to the origin of cysts in the floor of mouth.

The $1^{\text {st }}$ theory states that dermoids are a result of congenitally entrapped ectodermal tissue during closure of $1^{\text {st }}$ $\& 2^{\text {nd }}$ branchial arches. Occurs between third to fourth weeks of intrauterine life.

The $2^{\text {nd }}$ theory explains the acquired form of dermoid cysts may arise from surgical or accidental implantation of epithelium into the jaw mesenchyme leading to proliferation of epithelial cells in the deeper tissues.

Finally, the $3^{\text {rd }}$ theory states that these cysts are a variation of the thyroglossal pore cyst.

In our case, the patient did not have any history of trauma. While dermoid cysts can occur at any age, the highest incidence is in patients post puberty between $15-35$ years of age. Dermoid cysts develop slowly with patients not being aware of its presence until they are large enough to interfere with speech, mastication and swallowing. 6,7

The dermoid cysts of head and neck are common in the paediatric patients with the cysts usually limited to the periorbital region. Less common areas of occurrence are the dorsum of nose, suprasternal, thyroidal, and suboccipital regions..$^{8}$ In the study conducted by Pollard et al, $1976^{9}$ where 231 paediatric patients who underwent surgical enucleation of dermoid cysts reported that $84 \%$ lesions (194 cases) were located in the head and neck and $43 \%$ pertained to the periorbital region. The rest $57 \%$ were distributed throughout the scalp, ears, and neck

Dermoid cysts are classified as sublingual cyts or submental cysts based on the anatomic location of the cyst and geniohyoid muscles. ${ }^{7}$ The cyst which is located above the geniohyoid muscle is the sublingual cyst and those below the geniohyoid muscle is the submental cyst. In case of sublingual cyst, the patient will have displaced tongue, difficulty in breathing if extremely large and also difficulty in speech, mastication and swallowing. Swelling in the submental region results in "double chin" appearance. Sometimes these lesions might become infected secondarily and in very rare cases they might undergo a malignant transformation. Hence, they are indicated for removal.

The management of dermoid cyst is surgical removal with complete enucleation. Sublingual cyst above the geniohyoid muscle is removed through an intraoral approach and submental cyst through an extra oral approach. The extra oral approach is also used for very large dermoid cysts including both the submandibular and submental spaces.10,11 The treatment chosen for this patient was enucleation via an 
intraoral approach. The patient was observed for 3 months post-surgery during which there was no pathological finding. ${ }^{6}$

Financial or other competing interests: None.

Disclosure forms provided by the authors are available with the full text of this article at jemds.com.

\section{REFERENCES}

[1] Vieira EMM, Borges AH, Volpato LER, et al. Unusual dermoid cyst in oral cavity. Case Rep Pathol 2014;2014:389752.

[2] Koca H, Seckin T, Sipahi A, et al. Epidermoid cyst in the floor of the mouth: report of a case. Quintessence Int 2007;38(6):473-7.

[3] Menditti D, Laino L, Ferrara N, et al. Dermoid cyst of the mandibula: a case report. Cases J 2008;1(1):260.

[4] Patel H, Mayl J, Chandra B, et al. Dermoid of the oral cavity: case report with histopathology correlation and review of literature. J Radiol Case Rep 2016;10(12):19-27.
[5] Ueno T, Takayama R, Osada SI, et al. Epidermoid cyst arising on the body of the tongue: case report and literature review. J Nippon Med Sch 2018;85(6):343-6.

[6] Paradis J, Koltai PJ. Pediatric teratoma and dermoid cysts. Otolaryngol Clin North Am 2015;48(1):121-36.

[7] Taylor CM, Phan J, Shipchandler TZ. Enlarging floor of mouth mass. JAMA Otolaryngol Neck Surg 2017;143(2):189-90.

[8] Pryor SG, Lewis JE, Weaver AL, et al. Pediatric dermoid cysts of the head and neck. Otolaryngol Head Neck Surg 2005;132(6):938-42.

[9] Pollard ZF, Harley RD, Calhoun J. Dermoid cysts in children. Pediatrics 1976;57(3):379-82.

[10] Eken M, Evren C, Sanli A, et al. An alternative surgical approach for sublingual dermoid cysts: a case report. Kulak Burun Bogaz Ihtis Derg 2007;17(3):176-8.

[11] Agaimy A, Raab B, Bonkowsky V, et al. Intestinal-type adenocarcinoma arising in a congenital sublingual teratoid cyst. Virchows Arch 2007;450(4):479-81. 